\title{
Cine CMR diastolic function parameters in acute ST-elevation MI (STEMI) patients are associated with cardiac injury and left ventricular strain
}

\author{
Ana Barac ${ }^{*}$, Gopal Ghimire ${ }^{2}$, Jyotshana Shrestha², Manuel A Gonzalez², William O Suddath², Augusto D Pichard², \\ Lowell F Satler², Ron Waksman², Anthon R Fuisz², Gaby Weissman²
}

From 2011 SCMR/Euro CMR Joint Scientific Sessions

Nice, France. 3-6 February 2011

\section{Objective}

The aim of this study was to investigate associations between different parameters of diastolic function assessed from cine CMR, biomarkers of cardiac injury and left ventricular function and strain in patients with STEMI.

\section{Background}

Presence of diastolic dysfunction in patients with history of myocardial infarction represents a marker of adverse outcomes. However, its role in acute ST-elevation myocardial infarction (STEMI) is not fully elucidated. Cardiovascular magnetic resonance (CMR) allows quantitative measurement of volumetric changes that occur during diastole and form basis for calculation of different parameters of diastolic function. The relationships between these parameters, LV systolic function and strain, and markers of cardiac injury in STEMI are unknown.

\section{Methods}

Thirty patients with acute STEMI undergoing primary PCI were prospectively enrolled and underwent CMR imaging and 2D echocardiography within 48 hours of admission. CMR images were planimetered (Qmass, Medis, The Netherlands) in all slice positions across all temporal phases to calculate diastolic parameters: E/A ratio, peak filling rate (PFR and nPFR-normalized value for stroke volume), time to peak filling rate (TPFR), and diastolic volume recovery $\left(\mathrm{DVR}_{80}\right.$ - proportion of diastole required to recover $80 \%$ stroke volume). Longitudinal, radial and circumferential strain were assessed from

Washington Hospital Center/Georgetown University Hospital, Washington, DC, USA

Full list of author information is available at the end of the article standard echocardiographic views using 2D speckletracking software (2D CPA, TomTec, Germany). All patients had serial troponin values (at least three) measured.

\section{Results}

Median troponin value was $34 \mathrm{ng} / \mathrm{mL}$ (IQR 15.8-101.8) and median time from symptom onset to reperfusion was 194 minutes (IQR 158-277). Normalized PFR and $\mathrm{DVR}_{80}$ were associated with peak troponin I levels $(\mathrm{r}=-0.36, \mathrm{P}=0.049$, and $\mathrm{r}=-0.41, \mathrm{P}=0.011$ respectively). $\mathrm{LV}$ ejection fraction as well as global LV longitudinal strain correlated with nPFR $(\mathrm{r}=0.432, \mathrm{P}=0.017$ and $\mathrm{r}=-0.565$, $\mathrm{P}=0.010$ respectively) but the association with $\mathrm{DVR}_{80}$ was not significant $(r=0.277, P=0.18$ and $r=-0.232$,

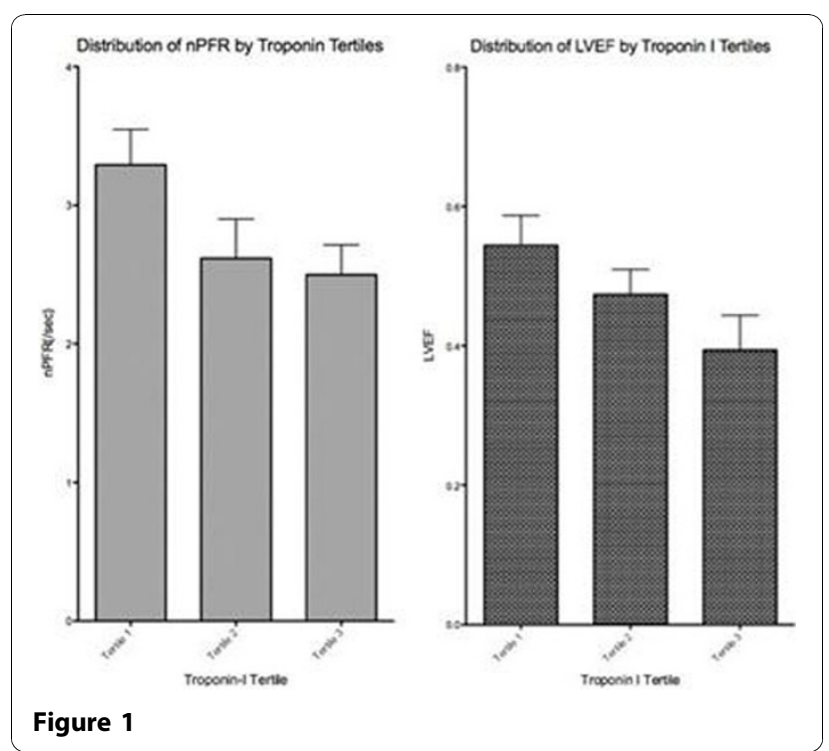


$\mathrm{P}=0.24$, respectively). Patients in the lowest time to reperfusion tertile had significantly higher nPFR compared to patients in the highest tertile $\left(3.32+0.84 \mathrm{~s} \mathrm{~s}^{-1}\right.$ vs $\left.2.27+0.52 \mathrm{~s}^{-1}\right)$. Figure 1 .

\section{Conclusions}

In acute STEMI patients diastolic function parameters by cine CMR imaging predict the extent of cardiac injury and are associated with the time to reperfusion. The role of these new measures of myocardial function in prognosis post STEMI remains to be investigated.

\section{Author details}

'Washington Hospital Center/Georgetown University Hospital, Washington,

DC, USA. ${ }^{2}$ Washington Hospital Center, Washington, DC, USA.

Published: 2 February 2011

- Convenient online submission

- Thorough peer review

- No space constraints or color figure charges

- Immediate publication on acceptance

- Inclusion in PubMed, CAS, Scopus and Google Scholar

- Research which is freely available for redistribution 